\title{
Intraoperative neuromonitoring and other techniques limiting the number of complications in thyroid surgery
}

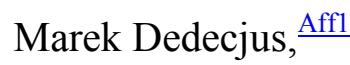

Corresponding Affiliation: Aff1

\begin{tabular}{|l|l|l|l||}
\hline \multicolumn{2}{|l|}{ ArticleInfo } \\
\hline \hline ArticleID & $:$ & 195 \\
\hline \hline ArticleDOI & $:$ & $10.1186 / 1756-6614-8-S 1-A 7$ \\
\hline \hline ArticleCitationID & $:$ & A7 \\
\hline \hline ArticleSequenceNumber & $:$ & 7 \\
\hline \hline ArticleCategory & $:$ & Meeting abstract \\
\hline \hline ArticleFirstPage & $:$ & 1 \\
\hline \hline ArticleLastPage & $:$ & 2 \\
\hline \hline ArticleHistory & $:$ & $\begin{array}{l}\text { RegistrationDate } \\
\text { OnlineDate }\end{array}$ \\
\hline \hline & & $\begin{array}{l}\text { Dedecjus; licensee BioMed Central Ltd.2015 } \\
\text { This article is published under license to BioMed Central } \\
\text { Ltd. This is an Open Access article distributed under the } \\
\text { terms of the Creative Commons Attribution License } \\
\text { http://creativecommons.org/licenses/by/4.0), which permits }\end{array}$ \\
\hline ArticleCopyright & $: \begin{array}{l}\text { unrestricted use, distribution, and reproduction in any } \\
\text { medium, provided the original work is properly cited. The } \\
\text { Creative Commons Public Domain Dedication waiver } \\
\text { http://creativecommons.org/publicdomain/zero/1.0/) applies } \\
\text { to the data made available in this article, unless otherwise } \\
\text { stated. }\end{array}$ \\
\hline
\end{tabular}

Aff1

Department of Oncological Endocrinology and Nuclear Medicine, Center of Oncology, Maria Skłodowska-Curie Memorial Institute, Warsaw, Poland

Spring School of Thyroidology organized by the Polish Thyroid Association 2014: abstracts of invited lectures

Spring School of Thyroidology organized by the Polish Thyroid Association 2014

Miedzyzdroje, Poland

23-24 May 2014

Publication of this supplement was funded by the Polish Thyroid Association. The Supplement Editors declare that they have no competing interests.

Meeting abstracts

Andrzej Lewinski

Mariusz Stasiolek 
Evolution of surgical techniques, together with progress in other fields of medicine (particularly in anesthesiology) limited - practically to zero - the mortality in thyroid surgery. Further development in thyroid surgery is directed towards limitations of postoperative complication rates.

The specific complications after thyroid surgery are hypoparathyroidism and recurrent laryngeal nerve (RLN) palsy (uni- or bilateral). The former, although mostly transient in character, has a frequency reaching up to $60 \%$ in cases of total thyroidectomy with central neck dissection because of thyroid cancer. At present, only meticulous preparation by experienced surgeons, together with PTH and calcium concentration monitoring, may be helpful in prevention and early diagnosis of hypoparathyroidism. Subsequent substitutive therapy with calcium and vitamin D metabolites should prevent hypocalcaemia.

Recent two decades was the time of intensive development of intraoperative neuromonitoring (IONM) of laryngeal nerves. Nowadays this technique, although still developing, has a stable place in thyroid surgery. Intraoperative neuromonitoring - at its present form - cannot prevent laryngeal nerve palsy, nevertheless together with stage thyroidectomy and careful preparation allows to avoid the most serious complication in thyroid surgery - bilateral RLN palsy. Recently developed continuous intraoperative neurmonitoring of vagal nerve is a promising tool and probably the next step in modern prevention of RLN palsy. Efforts in further development and standardization of the technique will hopefully result in the technique of IONM, allowing not only to intraoperatively diagnose but also to prevent RLN palsy. Further efforts are needed in limiting the invasiveness of the procedure. 